\title{
Understanding Reporting and Problem-Solving Behaviors in a High Reliability Organization: A Case Study in a Spanish Nuclear Company
}

\author{
Joaquín Navajas, Eulàlia Badia
}

Sociotechnical Resear Centre of Centro de Investigaciones Energéticas Medioambientales y Tecnológicas (CIEMAT), Madrid, Spain Email: Joaquin.navajas@ciemat.es, Eulalia.badia@ciemat.es

How to cite this paper: Navajas, J., \& Badia, E. (2020). Understanding Reporting and Problem-Solving Behaviors in a High Reliability Organization: A Case Study in a Spanish Nuclear Company. Psychology, 11, 1401-1419.

https://doi.org/10.4236/psych.2020.119090

Received: August 4, 2020

Accepted: September 26, 2020

Published: September 29, 2020

Copyright $\odot 2020$ by author(s) and Scientific Research Publishing Inc. This work is licensed under the Creative Commons Attribution International License (CC BY 4.0).

http://creativecommons.org/licenses/by/4.0/

\section{(c) (i) Open Access}

\begin{abstract}
The safety of high-reliability organizations is a factor resulting from the interaction between technology and organizational factors. The existence of a system to openly report incidents and without being afraid is paramount for safety. Previous research has identified organizational factors that foster or inhibit employees' participation in reporting as well as several organizational dilemmas. From this theoretical approach, this research presents a case study in a Spanish nuclear organization to understand how the event reporting system is perceived by its workers. Researchers carried out focus groups, which were designed to generate discourse around the organization's reporting system. Participants' discourse was analyzed to identify key interpretative repertoires. Results obtained show two main aspects related with the notifying and problem-solution behaviors: 1) the ineludible cultural nature of the reporting system and 2) the misleading relationship between reporting and problem-solving. These findings should be considered in order to manage the safety in risky industry.
\end{abstract}

\section{Keywords}

Reporting Culture, Organizational Culture, Safety Culture, Nuclear Industry, Interpretative Repertoires

\section{Introduction}

This paper aims to understand how the event reporting system is perceived in a Spanish nuclear industry organization and intends to enhance knowledge on factors related to reporting system perception and problem resolution approaches. The purpose is to identify factors determining participation in the organization's 
reporting system. To do that, the "interpretative repertoires" (Potter \& Wetherell, 1987) of focus group participants regarding the performance of their organizational reporting system were analyzed from a qualitative approach.

Prior to sharing study results, the significance of reporting systems in high reliability organizations and their inherent relationship to safety is discussed. The approach taken by the nuclear industry and on recent scientific literature data, will be assessed in detail. The common ground of all approaches is the assumption that having a participative reporting system opened to all employees contributes to increased organizational safety.

\subsection{Reporting System in High Reliability Organizations}

The safety of high reliability organizations (hereinafter, HRO), such as nuclear power plants, chemical processing facilities, or health systems, is conceived as a factor resulting from the interaction of technology and organizational components, especially considering technical and human subsystems are tightly interrelated (Perrow, 1984; Rasmussen, 1997).

From a sociotechnical approach, the analysis of risk and safety prevents simplistic assumptions based on a merely technological concept of safety (Hopkins, 2006; Le Coze, 2008; Le Coze, 2019). Thus, organizational culture became a relevant factor to better understand safety in high reliability organizations (Vaughan, 1996). Therefore, aspects related to the promotion of employee commitment or their participation in safety programs, become important.

From this point of view, the existence of a system to report incidents is paramount for safety. The safest organizations have implemented efficient strategies to report, identify and manage the consequences of error (Reason, 1997; K. Weick \& Sutcliffe, 2007). It is highly recommended to establish an open reporting system for near misses and accidents without fear of punishment (Health and Safety Executive, 2013). From an error management approach, it is considered that "Errors are ubiquitous. Errors cannot be completely prevented" (Frese \& Keith, 2015: p. 7). Thus, it is necessary to have systems allowing all organization members to communicate safety concerns.

According to (Reason, 1997; Reason, 1990) the reporting culture is a key aspect determining the safety of complex systems. Reason considers that the reporting culture should involve "voluntary" employee participation in safety information systems. It is important to emphasize the idea of participative willfulness, which is directly linked to how the organization manages guilt and penalizes error. It is worth mentioning that according to Reason "a no-blame culture is neither feasible nor desirable" (Reason, 1997: p. 295). Instead, establishing an environment of trust compatible with clear accountability, marking a clear line between acceptable and unacceptable behavior is really important (Reason, 1997).

\subsection{Reporting Systems within the Nuclear Industry}

Within the scope of the nuclear industry (IAEA, 2002a), the following problem reporting aspects are considered: 1) employees should have an attitude driving 
them to participate actively in incident reporting; 2) the lack of reporting would be a sign of weak safety culture and; 3 ) fostering the participation of employees entails ensuring those who report are not penalized by the organization.

With regards to active participation by all employees, a favorable attitude is shown by workforce's usage of "mechanisms for reporting on safety shortcomings and suggesting improvements" (IAEA, 1991: p. 28). To do that, the organization should foster an organizational culture favoring problem identification and resolution through participation of all employees.

Lack of reporting or personnel participation is, according to the International Atomic Energy Agency (IAEA), a symptom of "weak" safety culture. It would also reveal a lack of organizational awareness on the valuable knowledge that can be obtained from problematic events (IAEA, 2002a). To strengthen safety culture, it would be necessary to develop a reporting culture in which "all employees need to be encouraged to report even minor concerns" (IAEA, 2002a: p. 8).

Reporting failures and near-misses provide lessons that could prevent more severe events. In that sense, ensuring individuals are not afraid of reporting problems is quite important. The organizational culture should ensure that problem reporting is not retaliated. In other words, "(the employees) must believe that these reports are valued and that they and their colleagues will not be penalized or disciplined as a result of coming forward to make them." (IAEA, 2002a: p. 8).

Similarly, the Nuclear Regulatory Commission (NRC, 2004) links problem identification to an organizational culture in which employees do not fear retaliation in case they err. This idea is explicitly defined in the concept of Safety Conscious Work Environment (hereinafter, SCWE). SCWE is defined as an environment in which employees feel free to raise safety concerns, both to the management and to the NRC without fear of retaliation. The SCWE is a specific safety culture attribute that allows individuals to look for deficiencies and to ensure concerns are addressed. It is essential for the organization to ensure retaliation is not tolerated. In that sense, "an adverse action is deemed retaliatory if it is taken, in whole or in part, because the individual was engaged in a protected activity" (NRC, 2004: p. 5).

According to the Institute of Nuclear Power Operations (INPO), a SCWE is a healthy safety culture "component" that should include the implementation of a corrective action program accessible to all employees. The need for a culture allowing people to report openly and without being afraid is highlighted, so that "individuals feel free to raise nuclear safety concerns without fear of retribution, with confidence that their concerns will be addressed" (INPO, 2013: p. 27).

\subsection{Reporting Culture Determinants}

Recent research on reporting culture and their determinants, cover a large variety of high reliability industries, including the nuclear, petrochemical and health sectors. An important number of studies focus on quantifying the relationship between problem reporting and operational performance, the latter measured by quantitative and safety indicators (Hutchinson et al., 2009; Morrow et al., 2014). 
Generally speaking, there seems to be a clear consensus that the level of reporting is a key indicator of "health" in a high reliability organization (K. Weick \& Sutcliffe, 2007). Similarly, a lack of reporting would anticipate future operational problems. In this regard, a study reviewing twelve significant events into depth shows that organizational unreported precursors existed for many of such events (R. Taylor et al., 2017). The extent to which these reporting systems are used seems to indicate the level of organizational attention to safety. According to Hutchinson et al. (2009) there is a clear correlation between reporting culture and safety indicators within the hospital environment. Simons et al. (2015) consider that the reporting culture not only should be measured positively according to the global number of entries, because the implementation of many improvement programs could lead to decreased reporting even if safety culture improved.

Many studies identify leadership as a determining factor when it comes to organizational reporting. Visible commitment by management and leaders seems to be necessary conditions to ensuring employees make use of notifying systems. A leadership style based on management commitment and on a culture not penalizing error, has a clear influence on work processes (Hsu et al., 2010). Managers who in addition to their managerial skills, are perceived as approachable, seem to determine the frequency of reporting (Oltedal \& McArthur, 2011). Similarly, error feedback perception seems to be an organizational factor which significantly predicts the level of reporting (Richter et al., 2014). This feedback should be dynamic and understandable (J. Reason, 1997). A study with senior managers shows that safety culture refers mainly to the terms "just culture" and "reporting culture" (Fruhen et al., 2014).

Other studies also concluded that there are many hampering factors inhibiting reporting, aspects such as "extra work, skepticism, perhaps a natural desire to forget that the incident happened, (...) lack of trust and, the fear of reprisals" (Reason, 1997: p. 296) are highlighted. Within the healthcare context, Gifford \& Anderson (2010) consider that the lack of support from leaders and insufficient clarity of report results are some organizational barriers that hamper reporting.. A critical element is how employees perceive report undesirability by managers, which would entail "apparent concerns from staff that their reports would not be part of a just response, that bad news would not be welcome at more senior levels" (Taylor et al., 2017: p. 9). Håvold (2005) breaks down the reporting culture in aspects relating to the will to report (near misses or accidents) and the belief that reporting is important to safety.

Leadership perceived as unwillingness to accept responsibility or employees that are blamed, are two aspects with a negative impact (Behari, 2019; Halperin \& Bronshtein, 2019). The perception that reports will be censored before they reach system managers appears as a potential inhibiting barrier (Oswald et al., 2018).

According to (Gifford \& Anderson, 2010), the main individual factors that would hamper reporting are temporary pressure, lack of feedback and individual fear of retaliation as a result of reporting. (Nordlöf et al., 2015) point out that the 
main causes for omission are the time needed to write and describe an event and the shame of admitting an error or reckless act.

Accepting the importance of reporting problems does not necessarily imply that employees actually report (Mjadu \& Jarvis, 2018; Yang et al., 2020). A comparative study of sea transport organizations in Norway and Greece revealed that labor conditions and safety culture are the two main predictors of non-reporting within the industry (Nævestad et al., 2018).

A discretionary or volunteer aspect of reporting seems to be an underlying, relevant element that supports such reporting. In a qualitative study by Lekka \& Sugden (2011) which combined in-depth interviews with focus groups, it became evident that even if the reporting system was consistently used to report safety incidents, it was not always used for "minor" events. When it came to minor issues, personnel granted themselves the power to decide if reporting was necessary or not, so "staff would exercise their own judgment on whether such incidents should be reported” (Lekka \& Sugden, 2011: p. 448).

Some studies mention the difficulty of the actual act of reporting, that is, the challenge of writing down organizational aspects, some of which are complex. In this sense, Anderson et al. (2013) refer to the difficulty of laying out organizationally complex processes onto the report. The approach to problem resolution is also perceived as antagonist to the act of reporting (Sandberg \& Albrechtsen, 2018).

\subsection{Reporting and Organizational Dilemmas}

The reporting process has a socially-built dimension that closely ties reporting to its social context (van der Westhuizen \& Stanz, 2017). From this angle, it is important to consider the concept of "organizational dilemma" as a useful term to determine the meaning of reporting within organizations.

Organizational dilemmas are a dichotomy by which selecting an alternative seems to imply neglecting another. According to (Steiner, 1998), there is an organizational dilemma in situations when people are confronted with the need to make a decision (and to act) without having an alternative that seems clearly better than the rest. This type of situations tends to lead to organizational inefficiency when individuals are forced to act or, on the contrary, not to act when the action is needed. Furthermore, organizational dilemmas require some type of organizational learning (Steiner, 1998).

Some crucial dilemmas that may occur in organizations are: 1) the dilemma of productivity (Abernathy, 1979) which considers that "short-term efficiency and long-term adaptability are inherently incompatible" (Adler et al., 2009: p. 99) or 2) the innovator's dilemma (Christensen, 1997) which states that organizations tend to avoid radical innovations in order to satisfy its existing clientele. Multiple studies advocate the existence of different dilemmas within organizations from a variety of methodological and qualitative perspectives. In this way, Jonsson \& Zakrisson (2005) highlight the dilemmas that face leaders of non-governmental organizations. 
Studies on reporting show there are a number of dilemmas associated to the problem reporting act. According to Hor et al. (2010), the justification for the act of informing will depend on the meaning given to the act of reporting within a particular local context. After an ethnographic research, they pointed out that the reporting system and incident management system are highly linked to the local perception of accountability. Henriqson et al. (2014) refer to the "fear of vilification, social reprimand and work conflicts" as an organizational dilemma when it is understood that reporting is necessary (in the name of organization safety) but, on the other hand, it might be conflicting if it affects other colleagues.

\subsection{Subject of Study}

This research takes on a discursive, qualitative perspective to the study of organizations (Weick et al., 2005). From this standpoint, the aim of the study is to understand the nuclear sector workers' perception about reporting system and its link to problem-solving. To do that, the "interpretative repertoires" (Potter \& Wetherell, 1987) generated by focus group participants were qualitatively analyzed in order to understand the reasons why participants use (or did not use) the reporting system. And also to identify which factors, according to the organization's workers, would contribute to enhancing reporting system performance.

\section{Methodology}

\subsection{Case Study Organization and Context}

This research initiative is developed within the framework of the Consortium Agreement CIEMAT-IAEA (2016-19), Coordinated research Project on Organizational Cultural Basis for Successful Performance in NPPs IAEA-I22004 which is focused on analyzing reporting culture foundations in nuclear organizations.

The research is a case study of a Spanish nuclear industry. The organization, a public utility, of with 345 members, authorized this case study. Part of their staff is based at the headquarters and the other is distributed between two nuclear sites. To ensure the organization remains anonymous, in this paper it is referred to as NPC (Nuclear Public Company).

To provide context of the study, this organization underwent a safety culture self-assessment in 2017, with a special focus on strengthening its Reporting and Improvement System (hereinafter RIS), which had been designed and implemented by the quality department without full acceptance or usage by the workforce. The organization allowed researchers to carry out 6 focus groups (2 per site) as part of the Coordinated Research Project (CIEMAT-IAEA), with the aim of collecting accurate information on their reporting system.

\subsection{Method and Sample}

The qualitative measurement method used for this study was focus group. Groups were designed and led by the authors of this study for the purpose of learning more about RIS perception by organization employees. Two thematic areas guided 
focus group moderation:

1) Assessment of reporting system usage by the organization (both individually and organizationally).

2) Changes needed for RIS improvement as a problem-solving tool.

A total of 8 people participated in each group, all with a similar hierarchical position.

The employee sample was comprised of 48 workers selected by the organization.

Study sample selection considered Mintzberg's components (Mintzberg, 1979) different sites and the alignment of job categories. As a result, focus groups were formed as follows:

- Headquarters: 2 focus group with 4 individuals from the Technostructure and 4 individuals from Support.

- Nuclear facilities: 4 focus groups comprised of 4 individuals from Operational Core, 2 from Technostructure and 2 from Support.

Participants in every focus group had a similar job category (level $\mathrm{C}$ and level D employees) to ensure no hierarchical differences between them. Although the sample included all functional units, it excluded the participation of managers, executive positions and contractor personnel.

All group participants were asked for permission to record, transcribe and analyze the sessions. The anonymity and confidentiality of participants was ensured.

\subsection{Qualitative Analysis}

This study takes the analytical perspective of the Grounded Theory (Glaser \& Strauss, 1967), as well as a social constructionist concept by which language is considered a reality-building social practice (Garay et al., 2005). It is important to mention that the Grounded Theory pays special attention to the socially-built nature of reality (Edwards \& Potter, 2017; Gergen, 1985), with the aim of producing interpretations of study subjects (Annells, 1996; Glaser \& Strauss, 1967).

Within the scope of this paper, discourses were analyzed so as to identify key interpretive repertoires (J. Potter \& Wetherell, 1987). The social reality was approached inductively, meaning textual data immersion favored the understanding of cultural and social order aspects (Íñiguez, 2006). The qualitative analysis of interpretative repertoires provides recurrent patterns of specific, accurate meaning formulations around the NPC reporting system, showing how employees "build" the RIS within their daily activities.

The analysis process followed the guidelines mentioned by (Taylor \& Bogdan, 2000), referred to as "analysis in progress": data discovery, coding and relativization. It is important to know that both paper researchers participated in the coding phase, first assigning a code individually and then negotiating such code with the aim to establish end categories. Final interpretation of analysis-collected findings was also negotiated. It software MAXQDA (version 12) was used as a support tool to assign the codes (Rädiker \& Kuckartz, 2020). 


\section{Results}

The results of the analysis give information about the two areas used to design the participative process (Assessment of RIS and proposed changes).

\subsection{Perception of the Reporting System}

The qualitative analysis reveals that there are three aspects determining employees' perception of the reporting system.

\section{1) Unawareness of the system and its processes}

Most participants acknowledge they have never used the RIS. The reason why individuals do not use this application is supported by two main ideas:

- Lack of accurate information on the application and its use by the organization (what are incidences? what are corrective actions? which is the process followed after reporting?).

- As an IT application, RIS has inherent technological limitations, mainly that is a "cold system", "difficult to use" and "not fostering participation"). It also reveals the need for personnel to have a computer in their workstation, which is not always the case.

Participants repeatedly refer to the lack of knowledge to justify insufficient usage by the organization. The analysis shows there are differences between the sites. For example, whereas personnel at the headquarters referred to a generic lack of project implementation, station workers talked about aspects relating to management hierarchy. The main findings that justify the lack of use are shown in Table 1.

\section{2) RIS and problem resolution}

Three argumentative ideas structure the perception of RIS as a problem-resolution tool:

Cons:

Table 1. Summary of main arguments used to explain the scarse organizational use of RIS.

\begin{tabular}{|c|c|}
\hline \multicolumn{2}{|c|}{ Unawareness of the system and its processes } \\
\hline Argumentative Ideas & Fragments \\
\hline Lack of information & $\begin{array}{l}\text { "I have little information on the tool" } \\
\text { "This thing is a bit confusing (...) because I did not } \\
\text { attend the course" }\end{array}$ \\
\hline IT application & $\begin{array}{l}\text { "I have never used it. I have no computer and they won't } \\
\text { let me have one" } \\
\text { "An IT system (...) does not encourage people to } \\
\text { report the incidences" }\end{array}$ \\
\hline $\begin{array}{l}\text { Lack of project } \\
\text { implementation (Headquarters) }\end{array}$ & $\begin{array}{l}\text { "P1: Nothing has been implementedl P2: Yes, } \\
\text { it is not sufficiently implemented" }\end{array}$ \\
\hline $\begin{array}{l}\text { Influence of mid-level } \\
\text { managers (Facility } 1 \text { ) }\end{array}$ & $\begin{array}{l}\text { "Sometimes you would like to enter something on RIS } \\
\text { but it does not suit your boss' agenda" }\end{array}$ \\
\hline $\begin{array}{l}\text { Lack of authorization to } \\
\text { record incidences (Facility 2) }\end{array}$ & "There is a filter. Not everyone can enter an RIS action" \\
\hline
\end{tabular}


- Tool not adding much benefit: There is consensus on the fact that the RIS does not contribute to solving problems, thus there is a questioning about its problem-solving capability. This is justified by the nature of recorded incidences ("Some incidences entered do not improve anything") and the IT nature of the reporting system ("Entering something on a PC and not following up actions properly...does not provide the benefits it should")

- There are other organizational reporting mechanisms: Personnel mention other problem-resolution mechanisms considered better than RIS, which is not seen as the natural option to solve organizational issues. The formality of this application is perceived negatively compared to other informal options (face-to-face communication).

"It is best to talk amongst us, to discuss the issue, to approach your boss directly and not to lose our shared dialog and understanding. RIS should be the very last option."

Pros:

- Problem institutionalization: The formality of this application is considered by some participants as a strength. In other words, they value positively that the system institutionalizes problems not solved using ordinary means.

"Formalizing certain aspects (...) to make them public and take a more formal approach, ensuring everyone knows the path to follow, making the acceptance and scheduling of your improvement proposal public, and forcing other stakeholders to respond somehow."

There are also different visions depending on the location. At the headquarters, it is linked to problem resolution but only when the issue is considered solvable ("I only enter it when something happened and I already have the solution"; "We know some things cannot be solved, so we do not enter them on RIS"). On the contrary, station personnel think solutions are not linked to the reporting system ("The RIS is talking the talk rather than walking the walk"; "It is a show to let others know how good we are, not to solve issues").

Main argumentative ideas relating to the RIS and its problem-resolution capabilities are shown in Table 2.

Table 2. RIS and its problem-resolution.

\begin{tabular}{cl}
\hline & RIS and problem resolution \\
\hline Argumentative Ideas & \multicolumn{1}{c}{ Fragments } \\
\hline "It is not effective" & "It is not an operational tool" \\
"It's more theoretical than practical" & "Most problems can be solved without entering them onto RIS" \\
\hline RIS vs. other & "RIS is used when the issue could not be solved" \\
\hline Problem institutionalization & "It formalizes certain aspects from our perspective (...)" \\
& that is the appeal of this application"
\end{tabular}




\section{3) RIS inhibitors}

The analysis shows five types of arguments justifying the system's limiting nature.

- No criterion: Consensus amongst all groups on the lack of a clear criterion determining what incidences or problems should be reported.

Person 1: "The feeling that non-important things are registered and that important things are not."

Person 2: "That's not a feeling. There is actually no criterion, meaning you enter an action in good faith because you think it is relevant enough, but there is no criterion."

- No relevance: Many participants say the irrelevance of incidences reported on a daily basis justifies why people do not report.

"It is either too much work or something so specific that it cannot benefit the entire organization"

It is considered irrelevant to report non-important aspects.

"If you enter it, you are making it more important than it actually is."

- Repercussions of reporting: It is said that reporting could lead to having personal issues with coworkers or managers. As a participant put it: "Reporting creates problems for you". This type of argument is common across different focus groups.

"They tell you: why did you enter that? And this? If you report. Water is cold, then Mr. X comes and says. Listen, why did you enter that? Are you aware of the mess you have caused?"

"People feel it is going to lead to problems, so you prefer to take shortcuts."

"It is used as a weapon, as something coercive: "I am going to enter an RIS action so you do this?"

- Work Overload: Some plant participants say that in addition to leading to personal drawbacks, it may actually increase the workload.

"This sometimes turns into more work, into an overload."

"It leads to a work turmoil which eventually causes obstacles and hampers daily activities."

- Auditable by the Regulator: Groups at the headquarters say that the fact this tool can be audited by the Regulator, is an obstacle. This characteristic seems to limit the type of registered issues.

"We know the RIS is looked at by external parties. When a Regulator inspection comes, they say. Show me the RIS, and if there are 8 or 9 actions... the Regulator loves to see open actions. I love for them to see those actions because they are not mine, but I need to be empathetic because I don't want them to see 6 actions assigned to someone."

Main argumentative ideas relating to the RIS inhibitors are shown in Table 3.

\subsection{Improvements for a More Efficient System}

The analysis shows that employees perceive the need to improve technical and organizational RIS elements before it can become an optimal reporting system. 
Table 3. RIS inhibitors.

\begin{tabular}{cl}
\hline & \multicolumn{1}{c}{ RIS inhibitors } \\
\hline Argumentative Ideas & \multicolumn{1}{c}{ Fragments } \\
\hline No criterion & "It is not a tool that clearly defines what is an incidence, \\
a problem or the means to solve them" & "Sometimes silly things get entered onto RIS, a tool that \\
No relevance & should only be used for serious stuff" \\
\hline Repercussions of reporting & "It seems to create more problems than it solves" \\
& prefer to take shortcuts" \\
\hline
\end{tabular}

\section{1) Technical conditions}

Three types of arguments relating to technical tool aspects are mentioned.

- Clarifying the purpose: All groups agree on the need to clearly and accurately define the purpose of the RIS, its benefit and the type of events to be reported:

"I think it is important to explain what it should be used for (...), not only entering issues and incidences but also solutions"

- Clarifying the link between this tool and safety.

"It should be more focused on work safety, on overall site improvement."

"RIS should not be an instrument by which you accuse yourself of administrative non-compliance, but rather a development element ensuring safe project implementation, with a more preventive approach, instead of a tool to admit guilt."

- Usage procedure and criteria: The need to have an usage procedure is mentioned ("there should be a work procedure for it, which is not the case, so that we know exactly what should be entered"), as well as the need to have specific training on RIS usage.

It seems evident, especially at the stations, that it is necessary to clarify RIS usage in relation to daily-used processes (such as work orders).

"Sometimes we enter RIS actions when it should actually be a work order."

Main argumentative ideas relating to the RIS technical conditions are shown in Table 4.

\section{2) Organizational conditions}

Three types of arguments relating to organizational aspects were mentioned as conditions to make the RIS tool more efficient:

- Senior management commitment: RIS success is linked to visible management commitment to the tool. It is also considered necessary to engage all organizational areas so that it is not considered only a tool used by the quality department:

"Management is the secret of success."

"If each one of our managers called us at the end of the month and said: some amber traffic lights should be red or green, then we would be more awareness". 
Table 4. RIS technical conditions.

\begin{tabular}{ll}
\hline & RIS technical conditions \\
\hline Argumentative Ideas & \multicolumn{1}{c}{ Fragments } \\
\hline Clarifying the purpose & "It is important to explain what it should be used for" \\
& "The RIS should not be used for everything. It is \\
& something specific for nuclear aspects." \\
\hline Usage procedure and criteria & "There should be a document containing the criteria" \\
& "RIS? From now on, use it for everything? And I said \\
& "but we have a work order here."
\end{tabular}

- Acceptance by mid-level managers: Similarly, RIS acceptance and commitment by mid-level managers is considered paramount to ensuring tool enhancement.

"I think the best option would be that once you talk to your boss, he or she would right away enter the issue onto the computer. That would be the best option."

- Blame-free environment: To ensure RIS success, it is considered paramount to have an organizational culture which does not penalize reporting, which does not seek to blame and which facilitates fear-free usage of this tool.

"Having the freedom to do it without thinking you might make enemies."

"More effective and not focused on looking for someone to blame."

Main argumentative ideas relating to the RIS organizational conditions are shown in Table 5.

\section{Discussion}

The commitment and participation in reporting systems of employees' at all organizational levels are key elements for the safety of HROs (Reason, 1997). From this perspective, the aim of this study is to understand which main factors contribute to the perception and usage of reporting systems by workers in a Spanish nuclear industry organization. Some organizational logics behind reporting processes are revealed when the reasons that drive personnel to report (or not to report, as it happens in the organization of study) are adequately understood.

Results obtained in this study show two key aspects that need further discussion: 1) the ineludible cultural nature of the reporting system and 2) the misleading relationship between reporting and problem-solving.

\section{1) The ineludible cultural nature of the reporting system}

Safety culture is one of the safety pillars of HROs. Reference agencies within the nuclear industry inevitably link the existence of a strong, healthy safety culture to a solid reporting system (INPO, 2013; NRC, 2004). Participation in reporting systems by all organization employees becomes paramount (IAEA, 2002a). Scientific literature has identified organizational factors fostering orhampering the level of participation by employees. Numerous studies agree on the fact that leadership, of both executives and managers, is the crucial element determining the system's operational performance success (Reason, 1997). In turn, leadership influences the existence of a "blame-free" organizational culture that promotes reporting (Behari, 2019; R. Taylor et al., 2017). 
Table 5. RIS organizational conditions.

\begin{tabular}{cl}
\hline & RIS organizational conditions \\
\hline Argumentative Ideas & \multicolumn{1}{c}{ Fragments } \\
\hline $\begin{array}{c}\text { Engagement of management and } \\
\text { the rest of the organization } \\
\text { [Headquarters] }\end{array}$ & $\begin{array}{c}\text { "Management is the secret of success" } \\
\text { "If this is a tool for improvement, it should be available } \\
\text { for everyone" }\end{array}$ \\
\hline $\begin{array}{c}\text { RIS and the line of command } \\
\text { [Facility 2] }\end{array}$ & $\begin{array}{c}\text { "If you ask your bosses, whatever they respond } \\
\text { may condition you" } \\
\text { "Managers have no interest" }\end{array}$ \\
RIS and a blame-free \\
environment
\end{tabular}$\quad \begin{aligned} & \text { "Having the freedom to do it without thinking you } \\
& \text { might make enemies" } \\
& \text { "It should be more effective and not focused on } \\
& \text { looking for someone to blame" }\end{aligned}$

In the case of NPC, the reporting system is, a priori, open to all organizational levels. The quality department has designed a system according to common nuclear industry standards and requirements. Despite its design, incidence reporting on the system is limited and far from meeting the expectations of organizational managers. Is it because the tool is poorly designed? Is it because of inherent IT tool difficulties? This study coincides with others focusing on the relevance of cultural aspects associated to reporting (van der Westhuizen \& Stanz, 2017).

Firstly, the need to clarify the act of reporting becomes clear. Results show the need to accurately determine what should be reported. Individuals doubt on "what to report", "what is an incidence" or where RIS stands in relation to other mechanisms. It is worth mentioning that the definition of what should be reported is determined by the organization, applying criteria which do not depend on employees.

Secondly, the analysis shows that the act of reporting does not occur in an aseptic environment, but within a specific organizational context that eventually determines if reporting will take place or not. As shown by the analysis of groups, reporting in NPC takes place when the potential consequences of such reporting have been forecast. That means certain elements such as work overload, possible negative repercussions or how reporting may affect managers, seem to largely determine incidence reporting within the organization. Furthermore, it is revealed that reporting is conditioned by the fact that reported incidences are visible to the regulator.

The case study of NPC also shows that the organizational culture should be considered to understand the reporting behavior. Reporting is the result of the organizational value given by employees to the act of reporting. In other words, efficient system performance does not depend so much on the user-friendliness of the software or forms to complete, but rather on a set of organizational culture logics which determine the perception of what is suitable or not. The analysis of interpretative repertoires of employees reveals that the reporting system is not an objective procedure or aseptic instrument allowing workers to commu- 
nicate incidences to higher hierarchical levels. Reporting is part of a blueprint of organizational meanings forming the organizational culture.

Eventually, the analysis of organizational reporting programs is inevitably linked to the organizational culture to ensure a more effective operational performance. Thus, understanding the organizational culture helps to understand the very act of reporting (and vice versa).

\section{2) The misleading relationship between reporting and problem-solving}

The reporting behavior is a key aspect determining the safety of complex systems (Reason, 1997). Behaving indifferently to deficiencies is a sign that a weak safety culture exists (Weick \& Sutcliffe, 2007).

With regards to this case study, the high level of RIS dissociation from problem-solving processes, points to the artificiality and lack of operational life of the reporting system. The assessment of RIS as in-house marketing or a mere image proves that in certain operational levels within the organization, the system has no strong practical link to safety. In the face of problems, employees tend to talk amongst themselves or to go directly to a member of management. Based on this study it is possible to extrapolate that a reporting system on its own does not contribute positively to safety. To put it more bluntly, the mere organizational existence of reporting channels does not seem to provide sufficient guarantee that they will be used to solve operational problems and, in turn, to improve safety.

It is paradoxical that many NPC employees point to a fake use of the system to report problems for which the solution is known, and also to failure to use the system to address relevant issues for which there is no known solution. How can that deceptive balance be broken? How to boost a practical use of reporting systems? Study results suggest that strengthening the formal nature of the reporting system could be useful. In that regard, analysis results show that the notarized nature and capacity to institutionalize problems of this instrument are considered a strength.

On the other hand, results also reveal the existence of an underlying organizational dilemma (Steiner, 1998) in RIS usage. Such dilemma can be generically described as follows: "Global problems" vs. "Specific or silly problems". In a practical sense, the dilemma confronts ideal, desirable reporting based on "relevant" problems, against non-desirable, empty reporting of superfluous things. In terms of linguistic pragmatism (Levinson, 1989), the dilemma would be used to justify non-use of RIS to deal with daily, frequent issues. This characteristic of labor problems as minor or non-relevant, would justify the exclusion of formal reporting. Practical resolution of this dilemma at NPC implies justifying that it is not necessary to register minor incidences (categorized as "nonsense") so that the generation of false problems can be prevented.

In short, this study shows that even when people report on the system, the organizational value of such reporting should not be considered natural, nor linked to safety or to the identification of the most pressing problems faced by the organization. In fact, this case study reveals the paradox that it is possible to 
avoid registering complex problems (by simply reporting easily solvable issues), while justifying the need to report "relevant" problems in order to avoid the communication of daily incidences.

\section{Practical implications}

The results of this study have practical implications on the safety of high reliability organizations. On the one hand, they reveal that the act of reporting depends on a set of normative values. Thus, an increase in reporting levels would inevitably lead to questioning organizational culture aspects related to beliefs and values. On the other hand, it is also necessary to consider that the mere act of communicating events on the reporting system does not ensure the registration of essential organizational issues with the aim to address them. Care should be taken so that the resolution of potential reporting-related organizational dilemmas is commensurate with the safety significance of reported events.

\section{Study limitations}

This case study contains findings obtained solely from one organization. It would be interesting to compare these results to those of other organizations within this industry. In terms of design, it would also have been important to hold focus groups with middle managers and executives. This RIS system vision is confined to executing levels within the organization. It is important to emphasize that participants were selected by the organization, excluding executive positions and contractor personnel. This sampling characteristic should be considered since from a critical reflective perspective it is considered that methodological decisions are never neutral (Navajas et al., 2013).

\section{Conclusion}

The existence of an incident reporting system is a fundamental aspect in high reliability organizations (Reason, 1997; Weick et al., 2005). Such systems must allow the reporting by employees at all organizational levels. Therefore, it is crucial that the organizational culture encourages an attitude that leads to an active participation (IAEA, 2002b). From this theoretical approach, the aim of this study is to contribute to the knowledge of factors impacting on reporting behavior. Thus, a case study has been undertaken in an organization of the Spanish nuclear sector. Through the development of focus groups, the research has attempted to clarify what factors promote and hamper the use of the organization's reporting system. For so, a qualitative analysis of the "interpretative repertoires" of the focus group participants has been carried out.

The case study reveals that there are two aspects determining employees utilization of the reporting system. First, the inescapable influence of organizational culture on the reporting system, which determines what to report depending on people's forecast of the consequences. The qualitative analysis shows that reporting is the result of the organizational value given by employees to the act of reporting. In fact, the organizational cultural logics determine the perception of what is acceptable to report. Second, there is a paradoxical relationship between the reporting system and problem-solving. In this respect, the existence of re- 
porting channels does not ensure that the main operational problems are recorded and addressed. This study shows the existence of an organizational dilemma that confronts desirable reporting with not valuable reporting. The resolution of this dilemma would be used to justify the lack of use of the reporting system to notify minor incidents or the fake use of the system to report problems for which the solution is already known.

Future research regarding reporting behaviors should include all the organizational levels, such as strategic apex and middle line (Mintzberg, 1979) which, as prior studies have shown (Badia et al., 2020), may be determining diverse organizational subcultures in the Spanish nuclear industry.

\section{Conflicts of Interest}

The authors declare no conflicts of interest regarding the publication of this paper.

\section{References}

Abernathy, W. J. (1979). The Productivity Dilemma: Roadblock to Innovation in the Automobile Industry. Baltimore, MD: Johns Hopkins University Press.

Adler, P., Benner, M., Brunner, D.J., MacDuffie, J. P., Osono, E., Staats, B. R., Takeuchi, H., Tushman, M. L., \& Winter, S. G. (2009). Perspectives on the Productivity Dilemma. Journal of Operations Management, 27, 99-113. https://doi.org/10.1016/j.jom.2009.01.004

Anderson, J. E., Kodate, N., Walters, R., \& Dodds, A. (2013). Can Incident Reporting Improve Safety? Healthcare Practitioners' Views of the Effectiveness of Incident Reporting. International Journal for Quality in Health Care, 25, 141-150. https://doi.org/10.1093/intqhc/mzs081

Annells, M. (1996). Grounded Theory Method: Philosophical Perspectives, Paradigm of Inquiry, and Postmodernism. Qualitative Health Research, 6, 379-393. https://doi.org/10.1177/104973239600600306

Badia, E., Navajas, J., \& Losilla, J.-M. (2020). Organizational Culture and Subcultures in the Spanish Nuclear Industry. Applied Sciences (Switzerland), 10, 3454.

https://doi.org/10.3390/app10103454

Behari, N. (2019). Assessing Process Safety Culture Maturity for Specialty Gas Operations: A Case Study. Process Safety and Environmental Protection, 123, 1-10. https://doi.org/10.1016/j.psep.2018.12.012

Christensen, C. M. (1997). The Innovator's Dilemma: When New Technologies Cause Great Firms to Fail. Cambridge, MA: Harvard Business School Press.

Edwards, D., \& Potter, J. (2017). Some Uses of Subject-Side Assessments. Discourse Studies, 19, 497-514. https://doi.org/10.1177/1461445617715171

Frese, M., \& Keith, N. (2015). Action Errors, Error Management, and Learning in Organizations. Annual Review of Psychology, 66, 661-687. https://doi.org/10.1146/annurev-psych-010814-015205

Fruhen, L. S., Mearns, K. J., Flin, R., \& Kirwan, B. (2014). Safety Intelligence: An Exploration of Senior Managers' Characteristics. Applied Ergonomics, 45, 967-975. https://doi.org/10.1016/j.apergo.2013.11.012

Garay, A., Iñiguez, L., \& Martínez, L. M. (2005). La perspectiva discursiva en psicología social. Subjetividad y Procesos Cognitivos, 7, 105-130. 
Gergen, K. J. (1985). The Social Constructionist Movement in Modern Psychology. American Psychologist, 40, 266-275. https://doi.org/10.1037/0003-066X.40.3.266

Gifford, M. L., \& Anderson, J. E. (2010). Barriers and Motivating Factors in Reporting Incidents of Assault in Mental Health Care. Journal of the American Psychiatric Nurses Association, 16, 288-298. https://doi.org/10.1177/1078390310384862

Glaser \& Strauss (1967). The Discovery of Grounded Theory. London: Aldine Publishing Company.

Halperin, O., \& Bronshtein, O. (2019). The Attitudes of Nursing Students and Clinical Instructors towards Reporting Irregular Incidents in the Medical Clinic. Nurse Education in Practice, 36, 34-39. https://doi.org/10.1016/j.nepr.2019.02.018

Håvold, J. I. (2005). Safety-Culture in a Norwegian Shipping Company. Journal of Safety Research, 36, 441-458. https://doi.org/10.1016/j.jsr.2005.08.005

Health and Safety Executive (2013). Managing for Health and Safety HSG65 (pp. 1-62).

Henriqson, É., Schuler, B., van Winsen, R., \& Dekker, S. W. A. (2014). The Constitution and Effects of Safety Culture as an Object in the Discourse of Accident Prevention: A Foucauldian Approach. Safety Science, 70, 465-476. https://doi.org/10.1016/j.ssci.2014.07.004

Hopkins, A. (2006). What Are We to Make of Safe Behaviour Programs? Safety Science, 44, 583-597. https://doi.org/10.1016/j.ssci.2006.01.001

Hor, S., Iedema, R., Williams, K., White, L., Kennedy, P., \& Day, A. S. (2010). Multiple Accountabilities in Incident Reporting and Management. Qualitative Health Research, 20, 1091-1100. https://doi.org/10.1177/1049732310369232

Hsu, S. H., Lee, C.-C., Wu, M.-C., \& Takano, K. (2010). The Influence of Organizational Factors on Safety in Taiwanese High-Risk Industries. Journal of Loss Prevention in the Process Industries, 23, 646-653. https://doi.org/10.1016/j.jlp.2010.06.018

Hutchinson, A., Young, T. A., Cooper, K. L., McIntosh, A., Karnon, J. D., Scobie, S., \& Thomson, R. G. (2009). Trends in Healthcare Incident Reporting and Relationship to Safety and Quality Data in Acute Hospitals: Results from the National Reporting and Learning System. Quality \& Safety in Health Care, 18, 5-10.

https://doi.org/10.1136/qshc.2007.022400

IAEA (1991). Safety Series No. 75-INSAG-4 International Atomic Energy Agency, Vienna, 1991 Categories in the IAEA Safety Series. Safety Series Issue 75.

IAEA (2002a). Key Practical Issues in Strengthening Safety Culture INSAG-15 (p. 32). http://www-pub.iaea.org/MTCD/publications/PDF/Pub1137_scr.pdf

IAEA (2002b). Self-Assessment of Safety Culture in Nuclear Installations.

Íñiguez Rueda, L. (2006). Análisis del discurso. Manual para las ciencias sociales. Editorial UOC.

INPO (2013). Traits of a Healthy Nuclear Safety Culture (Issue May). http://nuclearsafety.info/wp-content/uploads/2010/07/Traits-of-a-Healthy-Nuclear-Saf ety-Culture-INPO-12-012-rev.1-Apr2013.pdf

Jonsson, G., \& Zakrisson, I. (2005). Organizational Dilemmas in Voluntary Associations. International Journal of Public Administration, 28, 849-856. https://doi.org/10.1081/PAD-200067373

Le Coze, J. (2008). Disasters and Organisations: From Lessons Learnt to Theorising. Safety Science, 46, 132-149. https://doi.org/10.1016/j.ssci.2006.12.001

Le Coze, J. C. (2019). Safety as Strategy: Mistakes, Failures and Fiascos in High-Risk Systems. Safety Science, 116, 259-274. https://doi.org/10.1016/j.ssci.2019.02.023 
Lekka, C., \& Sugden, C. (2011). The Successes and Challenges of Implementing High Reliability Principles: A Case Study of a UK Oil Refinery. Process Safety and Environmental Protection, 89, 443-451. https://doi.org/10.1016/j.psep.2011.07.003

Levinson, S. C. (1989). Pragmática. Editorial Teide.

Mintzberg, H. (1979). The Structuring of Organizations: A Synthesis of the Research. Upper Saddle River, NJ: Prentice Hall.

Mjadu, T. M., \& Jarvis, M. A. (2018). Patients' Safety in Adult ICUs: Registered Nurses' Attitudes to Critical Incident Reporting. International Journal of Africa Nursing Sciences, 9, 81-86. https://doi.org/10.1016/j.ijans.2018.09.001

Morrow, S. L., Kenneth Koves, G., \& Barnes, V. E. (2014). Exploring the Relationship between Safety Culture and Safety Performance in U.S. Nuclear Power Operations. Safety Science, 69, 37-47. https://doi.org/10.1016/j.ssci.2014.02.022

Nævestad, T.-O., Hesjevoll, I. S., \& Phillips, R. O. (2018). How Can We Improve Safety Culture in Transport Organizations? A Review of Interventions, Effects and Influencing Factors. Transportation Research Part F: Traffic Psychology and Behaviour, 54, 28-46. https://doi.org/10.1016/j.trf.2018.01.002

Navajas, J., Silla, I., Salabarnada, E., Muñoz, V., \& Badia, E. (2013). The Limits of the Photographic Act as a Metaphor for the Assessment of Organizational Culture. An Ethnographic Study of a High Reliability Organization. Safety Science, 59, 116-125. https://doi.org/10.1016/j.ssci.2013.05.007

Nordlöf, H., Wiitavaara, B., Winblad, U., Wijk, K., \& Westerling, R. (2015). Safety Culture and Reasons for Risk-Taking at a Large Steel-Manufacturing Company: Investigating the Worker Perspective. Safety Science, 73, 126-135. https://doi.org/10.1016/j.ssci.2014.11.020

NRC (2004). Policy Issue.

Oltedal, H. A., \& McArthur, D. P. (2011). Reporting Practices in Merchant Shipping, and the Identification of Influencing Factors. Safety Science, 49, 331-338.

https://doi.org/10.1016/j.ssci.2010.09.011

Oswald, D., Sherratt, F., Smith, S. D., \& Hallowell, M. R. (2018). Exploring Safety Management Challenges for Multi-National Construction Workforces: A UK Case Study. Construction Management and Economics, 36, 291-301. https://doi.org/10.1080/01446193.2017.1390242

Perrow, C. (1984). Normal Accidents: Living with High-Risk Technologies. Princeton, NJ: Princeton University Press.

Potter, J., \& Wetherell, M. (1987). Discourse and Social Psychology: Beyond Attitudes and Behaviour. New York: SAGE Publications Inc.

Rädiker, S., \& Kuckartz, U. (2020). Análisis de datos cualitativos con MAXQDA. Texto, Audio, Video.

Rasmussen, J. (1997). Risk Management in a Dynamic Society: A Modelling Problem. Safety Science, 27, 183-213. https://doi.org/10.1016/S0925-7535(97)00052-0

Reason, J. (1990). Human Error. Cambridge: Cambridge University Press. https://doi.org/10.1017/CBO9781139062367

Reason, J. (1997). Managing the Risks of Organizational Accidents. Abingdon-on-Thame: Routledge.

Richter, J. P., McAlearney, A. S., \& Pennell, M. L. (2014). Evaluating the Effect of Safety Culture on Error Reporting: A Comparison of Managerial and Staff Perspectives. American Journal of Medical Quality, 30, 550-558.

https://doi.org/10.1177/1062860614544469 
Sandberg, E., \& Albrechtsen, E. (2018). A Study of Experience Feedback from Reported Unwanted Occurrences in a Construction Company. Safety Science, 107, 46-54. https://doi.org/10.1016/j.ssci.2018.03.028

Simons, P. A. M., Houben, R., Vlayen, A., Hellings, J., Pijls-Johannesma, M., Marneffe, W., \& Vandijck, D. (2015). Does Lean Management Improve Patient Safety Culture? An Extensive Evaluation of Safety Culture in a Radiotherapy Institute. European Journal of Oncology Nursing, 19, 29-37. https://doi.org/10.1016/j.ejon.2014.08.001

Steiner (1998). Organizational Dilemmas as Barriers to Learning. The Learning Organization, 5, 193-201. https://doi.org/10.1108/09696479810228577

Taylor, R., May, J., Weyman, A., \& Carhart, N. (2017). Understanding Organisational and Cultural Precursors to Events. Proceedings of the Institution of Civil Engineers Forensic Engineering, 170, 124-133. https://doi.org/10.1680/jfoen.17.00006

Taylor, S., \& Bogdan, R. (2000). Introducción a los métodos cualitativos. In Introducción a los métodos cualitativos de investigación (p. 301). Ediciones Paidos.

van der Westhuizen, J., \& Stanz, K. (2017). Critical Incident Reporting Systems: A Necessary Multilevel Understanding. Safety Science, 96, 198-208.

https://doi.org/10.1016/j.ssci.2017.04.004

Vaughan, D. (1996). The Challenger Launch Decision: Risky Technology, Culture, and Deviance at NASA. Chicago, IL: The University of Chicago Press. https://doi.org/10.7208/chicago/9780226346960.001.0001

Weick, K. E., Sutcliffe, K. M., \& Obstfeld, D. (2005). Organizing and the Process of Sensemaking. Organization Science, 16, 409-421.

https://doi.org/10.1287/orsc.1050.0133

Weick, K., \& Sutcliffe, K. (2007). Managing the Unexpected Resilient Performance in an Age of Uncertainty (p. 8). San Francisco, CA: Jossey-Bass.

Yang, R., Pepper, G. A., Wang, H., Liu, T., Wu, D., \& Jiang, Y. (2020). The Mediating Role of Power Distance and Face-Saving on Nurses' Fear of Medication Error Reporting: A Cross-Sectional Survey. International Journal of Nursing Studies, 105, Article ID: 103494. https://doi.org/10.1016/j.ijnurstu.2019.103494 